EMBRYARIDDLE
Aeronautical University

SCHOLARLY COMMONS
International Journal of Aviation, Aeronautics, and Aerospace

\title{
Analysis of Runway Incursion Trends: Implications for Cost- Benefit Analysis of Mitigation Investments
}

David C. Ison

Northcentral University, flyandteach@gmail.com

Follow this and additional works at: https://commons.erau.edu/ijaaa

Part of the Economics Commons, and the Risk Analysis Commons

\section{Scholarly Commons Citation}

Ison, D. C. (2020). Analysis of Runway Incursion Trends: Implications for Cost-Benefit Analysis of Mitigation Investments. International Journal of Aviation, Aeronautics, and Aerospace, 7(1).

https://doi.org/10.15394/ijaaa.2020.1438

This Article is brought to you for free and open access by the Journals at Scholarly Commons. It has been accepted for inclusion in International Journal of Aviation, Aeronautics, and Aerospace by an authorized administrator of Scholarly Commons. For more information, please contact commons@erau.edu. 
Runway incursions, defined as an occurrence in which a vehicle, aircraft, or person makes an unauthorized transgression onto a runway, have been a focus of aviation safety stakeholders due to their potential for substantial loss of life in the event of a collision. The National Transportation Safety Board (NTSB, n.d.) has long advocated for incursion mitigation in the form of technology, training, and research. The Federal Aviation Administration (FAA) has implemented mandatory reporting of incursions and tracks such events in its Runway Incursion Database (RWS) (FAA, 2017). Additionally, the FAA has invested a substantial amount of resources into runway incursion mitigation strategies, for example, improving airport signage and markings, increasing pilot education outreach, and the installation of various technologies to improve situational awareness and aircraft position monitoring (FAA, 2007; 2017). The implemented technologies include Airport Surface Detection Equipment - Model X (ASDE-X) and Runway Status Lights (RWSL) systems (FAA, 2007; Office of the Inspector General - Department of Transportation [OIGDOT], 2018).

As can be expected, these improvements come at a high cost. According to the OIGDOT (2018), from 2005 through 2011, the total cost of the ASDE program was $\$ 549.8$ million, with unexpected overages accounting for approximately $\$ 100$ million of the total expenditures. While the total spent on RWSL was not readily available within the literature, historical costs can provide an estimate. In 2014, the allotment for RWSL was $\$ 35.2$ million, in 2015 it was $\$ 41.7$ million, and in 2016 it was $\$ 22.6$ million with an additional $\$ 1.57$ million for sustainment costs. Thus the total cost over this three-year period was over $\$ 101$ million (FAA, 2016). Considering the RWSL program has been in development since 2004, the total cost, at what appears to average $\$ 33$ million per annum, is likely to be significant (Kuffner \& Perkins, 2009). The problem is that the effectiveness of these investments has not been substantially empirically analyzed thus, little is known about the costs versus benefits of the various implemented improvements (Kuffner \& Perkins, 2009; Schönefeld \& Möller, 2012; Van Eekeren, Wright, and Čokorilo, 2018).

\section{Defining Runway Incursions}

\section{Literature Review}

According to the FAA, runway incursions are defined as "any occurrence at an aerodrome involving the incorrect presence of an aircraft, vehicle or person on the protected area of a surface designated for the landing and takeoff of aircraft" (FAA, 2008, p. 37). This definition was adopted from the International Civil Aviation Organization (ICAO) to better align with international aviation safety standardization in 2008 (FAA, 2008). The ICAO and the FAA categorize the severity of incursions as:

- Category A: A serious incident in which a collision was narrowly avoided 
- Category B: An incident in which separation decreases and there is a significant potential for collision, which may result in a time-critical corrective/evasive response to avoid a collision

- Category C: An incident characterized by ample time and/or distance to avoid a collision

- Category D: Incident that meets the definition of runway incursion such as the incorrect presence of a single vehicle/person/aircraft on the protected area of a surface designated for the landing and takeoff of aircraft but with no immediate safety consequences (FAA, 2017).

The FAA (2017) further delineates that category A and B incursions are "serious" (p. 43) versus category $\mathrm{C}$ and $\mathrm{D}$, which are generally considered lower risk. The amendment to the definition of runway incursions in 2008 resulted in a substantial jump in category $\mathrm{C}$ and $\mathrm{D}$ events and should be noted as a result of this change rather than a "real" dramatic boost in such occurrences (FAA, 2008; 2017).

\section{Trends in and Responses to Runway Incursions}

Considering forecasted rises in global air traffic, runway incursions will continue to be a substantial concern for aviation safety. Mrazova (2014) explained that runway safety is of particular concern due to traffic growth, with runway incursions set to rise along with traffic if interventions are not adopted. Depending on the airport, it is estimated that a $20 \%$ increase in traffic volume may increase the potential for single runway incursion rates by up to $140 \%$ (Schönefeld \& Möller, 2012). To assist in mitigating such threats to safety, sufficient investment in proven improvement strategies were noted to be essential to mitigating safety threats such as incursion (Chen, Zhang, \& Chen, 2016). Morrison and Winston (2008) described FAA expenditures for air traffic system improvement, noting that "given the expected growth in air travel, it is incumbent on the FAA to make efficient use of its preferred mechanism - public spending... Its failure to do so will compound the inefficiencies" (p. 670). The question also remains if such investments are effective in reaching desired outcomes: "surprisingly, little effort has been made to assess the efficacy of FAA's expenditures" (Morrison \& Winston, 2008, p. 670). Reinforcing the responsible use of money to fix aviation system problems, especially in safety, Hong-bing and Qing-qing (2015) stated that "inadequate safety investment could affect safety level, and yet misallocation of investment would result in a waste of resources... Thus it's of great significance to properly grasp the safety investment direction, and allocate reasonably the ratio to each aspect" ( $p$. 780). Van Eekeren, Wright, and Čokorilo (2018) further stated that "the law of diminishing return, however, might pose future financially motivated restrictions. Therefore cost-effective runway risk-mitigations are necessary" (p. 261).

One relatively simple safety enhancement that was outlined in this study is the airport "hot spot." These are locations on airports that have commonly been involved with runway incursions or have characteristics attributable to higher 
incursion probabilities such as complex taxiway and runway intersection geometry. Hot spots are made known to pilots via circles highlighting the problem locations on airport diagrams (Schönfeld \& Möller, 2102). Though there has not been formal research on the effectiveness of hot spots, the relatively low cost of the intervention and its ability to potentially increase pilot situational awareness are laudable (Mrazova, 2014).

Mrazova (2014) presented counts of the various types of incursions, including annual totals for the years 2009-2014. While the number of incursions peaked between 2012 and 2013, Mzazova (2014) stated that "we can see decreasing rate[s] of runway incursion[s] in 2014 compared to 2013" (p. 73). Two prominent considerations about this observation are that the numbers presented were counts of incursions, not rates of incursion (e.g., per 1,000,000 operations), and it is difficult to determine real trends over just one year. Further, the 2014 total number of incursions exceeded the totals for years 2009-2011.

Schönefeld and Möller (2012) also illustrated that general aviation (GA) was the primary causal category of operations among runway incursions. The authors see this as problematic as "technical and financial constraints for most of the general aviation aircraft and smaller airports limit the use of runway incursion prevention technology" (Schönefeld \& Möller, 2012, p. 33). In essence, since the improvements offered by the FAA and European agencies focus on large, commercial airports with minimal GA traffic, the impact of incursion prevention systems may not be focused on the most suitable venues. Further, since GA operations involve less-experienced pilots with less sophisticated technologies, the systems may not have the expected influence (Schönefeld \& Möller, 2012).

\section{RWSL at Los Angeles International and Dallas-Fort Worth International Airports}

In order to address incursion concerns, two airports, Dallas-Fort Worth International (DFW) and Los Angeles International (LAX), were selected for RWSL prototype testing in 2003 and 2009, respectively. The system at LAX was considered operational in 2013 and 2005 for DFW (FAA, 2008). LAX was selected because "according to the Federal Aviation Administration, an earlier installation of lights greatly reduced the number of runway incursions at LAX, which had the most runway safety violations in the nation from 1999 to 2007" (Weikel, 2012, para. 2). According to FAA databases, from 1997-2007 LAX had six category A incursions and thirteen category B types (FAA, 2017b; 2001). DFW was selected due to high traffic volumes and having complicated airport layout (Russell, 2017). From 1997-2007, DFW had two category A events and four category B events (FAA, 2017b; 2001). The logic of significant investment to install incursion mitigation technologies at airports as large as LAX and DFW coupled with low general aviation traffic at both locations is perplexing, especially in light of comparisons with other potential candidate airports (Hong-bing \& Qing-qing, 
2015). A few examples of airports with notably higher incursion rates than those of LAX and DFW from 1999-2007 are outlined in Table 1.

\section{Cost-Benefit Analysis in Aviation Safety}

As is the case with any project that requires public funds to assist in their development, runway incursion mitigation is subject to accountability standards of the OIGDOT $(2008 ; 2018)$. Cost-benefit analysis of improvements is generally considered part of the analysis necessary to determine the allocation of finite resources to improve safety. As noted by Van Eekeren et al. (2018), "cost-effective runway risk mitigations are necessary" (p. 261) as an infinite source of funding for safety enhancements is not available. The authors estimated the total worldwide cost of runway accidents between 2015 and 2018 to be $\$ 20$ billion. Although the calculation of the cost of an aviation accident is exceptionally complex, Ferdman (2014) calculated that a single aviation accident involving one large commercial transport aircraft could have a total liability of $\$ 1$ billion.

As noted previously, Van Eekeren et al. (2018) highlighted that general aviation is involved in "by far the highest number of runway events" (p. 264). In terms of cost-benefit analysis, apparently the investment in groups that may achieve the highest benefit should be targeted, thus it would make sense to invest in airports with the highest rates of incursions particularly where general aviation activity interacts with commercial aviation on a regular basis (FAA, 1998; Rogerson, Lambert, \& Johns, 2013).

Rogerson et al. (2013) described a framework for program effectiveness analysis using layers of stakeholder and expert risk acceptance to determine if a project is not warranted, possibly, warranted, or warranted based upon the rate of incursions per 100,000 operations. In an example analysis, the study outlined the presumption of the need for incursion mitigation at certain airports based on the presence of a flight school. Out of fifteen airports, only seven met the threshold for warranted, two for possibly warranted, and four not warranted. An additional analysis of 29 airports showed that only two qualified for warranted intervention, sixteen for possibly warranted, and eleven for unwarranted. While many of the assumptions of the outlined model were theoretical, the study did indicate considerations for selective implementation of interventions with finite resources. Again, targeting problem populations (e.g., user groups and specific airports) being highlighted as key to the success of safety enhancement improvements.

Along similar lines, Stewart and Mueller (2013) found that looking for a break-even cost-benefit ratio decreases the likelihood of a safety-related event but does not waste resources. They noted that this approach is increasingly being used in aviation thus it lends itself to aviation problems, in this specific case to terrorism prevention, though, as noted by the authors, it could be more widely applicable to aviation safety problems (Stewart \& Mueller, 2013). 
Chen et al. (2016) also found that some of the highest returns on investments were in the areas of training and technology. Hong-bing and Qing-qing (2015) came to similar conclusions, noting that in order to maximize safety improvements, investments should be focused specifically on projects that have the most significant impact. The authors stated that productive safety investment was a function of the rate of safety improvement in contrast to total costs moreover, both direct and indirect costs and benefits should be considered. The study also showed that there is a point at which safety investment peaks regarding improvements, thus further investment may result in diminishing returns. Therefore, there is a balance to investment where too much can be a waste while not enough may not have sufficient impact.

An empirical framework for evaluating FAA investments in aviation system enhancements was developed by Morrison and Winston (2008) in response to the inadequate assessment of the efficacy of such investments. In alignment with other researchers, Morrison and Winston (2008) indicated that the proper balance of investment must be made as improper allocation could have negative impacts on safety. At the same time, it was noted that there had been an inadequate assurance that spending has been conducted most efficiently. Lastly, the authors stated that as is often the case in aviation, arbitrary and reactionary responses often dictate priorities of investment without empirical and more in-depth inquiry into the efficacy and value of these outlays (Morrison \& Winston, 2008).

In 2008, the Principal Assistant Inspector General for Auditing and Evaluation stated that RWSL is a "viable technology" (OIGDOT, 2008, p. 7) for runway incursion prevention. Relying on data collected at Dallas-Ft. Worth International Airport between October 2002 and February 2005, there was a 70\% decrease in incursions. As such, it was recommended that the FAA expedite the installation of RWSL at other locations. No considerations about cost and statistical verification of system impact were mentioned. Further, the author stated that "we did not rely on information contained in databases [sic] maintained by the Agency as part of this review. Therefore, we did not conduct a data reliability assessment" (OIGDOT, 2008, p. 15). This statement highlights the need to conduct empiricallybased research on the effectiveness of such investments.

\section{Method}

The purpose of this quantitative, correlational and causal-comparative study was to evaluate the impact of RWSL installation at LAX and DFW airports. Insight into the costs versus benefits of these installations was also explored.

\section{Sampling Procedures}

OPSNET data was collected for Dallas-Fort Worth International Airport (DFW) and Los Angeles International Airport (LAX) as these airports were early adopters of various runway safety improvements such as RWSL. Data was 
collected for the years 2001-2017 (2018 data was incomplete at the time of this study). Rates of incursions were calculated by dividing the total number of incursions by total airport tower operations (FAA, 2017).

Measures

Data from OPSNET was downloaded as comma-separated values (CSV) files and imported into Excel for initial data analysis including the calculation of rates and counts. From the resulting Excel worksheets, data was uploaded to SPSS for the calculation of Chi-square and Mann-Whitney $U$ tests. Excel was also used to produce graphs of counts and rates.

\section{Research Design}

The designs used in the study were correlational and causal-comparative. Spearman correlations were used to investigate the relationship of incursion rates with passage of time. Chi-square tests were utilized to assess associations and potential differences among observed and expected counts of incursions before and after RWSL installation at LAX and DFW airports. In cases of low incursion counts in which Chi-square and Fisher's Exact tests were not recommended, binomial tests were conducted (Field, 2013). Mann-Whitney $U$ tests were conducted to identify differences, if any, among incursion rates for the periods before and after the installations of RWSL at LAX and DFW airports.

\section{Statistical and Data Analysis}

\section{Results}

Incursions: LAX and DFW airport trends and differences. Counts of incursions during 2001-2012 at LAX were compared to counts for 2013-2017, and for DFW, the ranges were 2001-2004 versus 2005-2017. These ranges were based upon when the RWSL was considered operational at each airport. Due to low counts for A and B severity incursions, these were combined for each airport and were analyzed using a two-tailed binomial test. The proportion of $\mathrm{A}$ and $\mathrm{B}$ incursions occurring at LAX before RWSL of .86 $(n=6)$ was not significantly different than the expected $.697, p=0.646$ while the proportion after RWSL was operational of $.303(n=1)$ was not significantly different than the expected $.14, p$ $=0.646$. For DFW, the proportion of A and B incursions occurring before RWSL of $0.00(n=0)$ was not significantly different than the expected $.267, p=1.00$ while the proportion after RWSL was operational of $1.00(n=2)$ was not significantly different than the expected $.733, p=1.00$. Chi-square goodness-of-fit tests were used for analyzing $\mathrm{C}$ and $\mathrm{D}$ incursions for the periods before and after RWSL being completely operational at each airport (see Tables 2 and 3). Mann-Whitney $U$ tests were also conducted for each airport and severity category rate comparing the apposite years (see Table 4). Graphs of counts and rates for LAX and DFW airports, with trend lines, are provided in Figures 1 through 4. 


\section{Discussion}

Combined category A and B counts using two-tailed binomial tests did not indicate any significant changes from the periods before and after RWSL systems were considered to be operational. The low counts of A and B category incursions at both airports is notable in and of itself, as these were selected as critical airports at which to implement the systems. In fairness, before 2001, LAX did have some severe events, including a collision between two aircraft on a runway in nighttime conditions. However, overall data subsequent period after that event does not seem to support the emphatic nature of the impetus of expensive interventions. The low number of occurrences at DFW airport also calls into question the selection of such a large airport, requiring significant investment, to implement RWSL. In the cases of both LAX and DFW airports, there does not appear to be a significant change since the implementation of RWSL. Chi-square analyses of category $\mathrm{C}$ incursions for both LAX and DFW indicated significant increases in counts from those that would be expected based on traffic levels, yet for category D neither airport had significant differences.

Mann Whitney $U$ tests conducted on incursion rates indicated that there were no differences for category A, B, and D events when comparing periods before and after RWSL operational status. Category C events, however, did show significant increases between periods. Both sets of tests do not support initial claims by the literature that the potential impact of RWSL to reduce runways incursions by 70 to $80 \%$ cannot be verified in the scope of this study.

Analysis of LAX airport data indicated that both C and D category incursion counts and rates have been increasing. There were not enough $\mathrm{A}$ and $\mathrm{B}$ category events to provide a palpable trajectory (Figures 1 and 2). The only trendline with a good fit was for rates of $\mathrm{C}$ incursions $\left(R^{2}=0.8439\right)$. For DFW, there were no category B events, and there was no clear trend for A events. Category C events showed a clear upward trend with a large amount of yearly variation $\left(R^{2}=0.6571\right)$, while Category D had a negligible upward slope, with very low congruity (Figures 3 and 4). Both airports have seen total incursions increasing over time due to a rise in category $\mathrm{C}$ and $\mathrm{D}$ occurrences. For DFW, in particular, there was a noticeable jump in the $\mathrm{C}$ severity category following the adoption of the FAA's new incursion definition in 2008.

\section{Conclusion}

Considering these findings, it is evident that the data do not seem to support the claims of a significant reduction in incursions as outlined in the literature. Also, as both LAX and DFW are sizeable airports and have minimal general aviation operations, the combination of significant pavement infrastructures and ensuing construction costs coupled with a low to the non-existent population of aviation operations which are most responsible for incursions, calls into question the 
selection of these airports for investment for RWSL. In the current constrained government funding environment, investment in the least expensive intervention with the most impact is not only fiscally responsible but necessary in light of dwindling, scarce resources. It possible that the implementation of RWSL, particularly at LAX and DFW may have been rushed without a detailed statistical analysis of the realistic impact the system had during testing. Also, a candid and precise cost-benefit analysis would logically have been a pre-requisite before implementation. As previously outlined, there seems to have been a significant investment in RWSL in an environment that does not have a significant need for it.

The impact of RWSL on LAX and DFW airports does not appear to align with expectations based on the literature. When comparing periods before RWSL became active with those after implementation, no significant changes were noted in counts of A, B, and D events. Rates for A, B, and C also did not significantly differ. Graphical data appears to support these findings. This effort helps to ensure that large investments of public funds are spent on the solutions that provide the most benefit at the lowest cost being applied at the appropriate locations. The findings of this study advocate for further research on incursion trends and costeffective mitigation strategies targeted toward airports with substantial general aviation operations.

\section{Suggestions for Future Research}

Based on the findings within this study, the following suggestions for future research are provided:

- Regular monitoring and analysis of runway incursion trends utilizing statistical analysis

- Empirical study of cost-benefit ratios of FAA investments, particularly when requiring substantial resources from stakeholders and the tax-payer 


\section{References}

Chen, M., Zhang, Y., \& Chen, Y. (2016, October). Review on civil aviation safety investment research. 11th International Conference on Reliability, Maintainability and Safety (ICRMS) (pp. 1-5). IEEE.

FAA. (1998). Economic analysis of U.S. Department of Transportation investment and regulatory Federal Aviation Administration decisions -Revised Guide. Retrieved from https://www.faa.gov/regulations_policies/ policy_guidance/benefit_cost/media/ECONOMIC.pdf

FAA. (2007). FAA needs to improve ASDE-X management controls to address cost growth, schedule delays, and safety risks. Retrieved from https://www.oig.dot.gov/sites/default/files/WEB_ASDE-X_10-31-07.pdf

FAA. (2008). Runway safety report: June 2008. Retrieved from https://www.faa.gov/airports/runway_safety/publications/media/pdf/RSRe port08.pdf

FAA. (2016). Budget estimates: Fiscal year 2016. Retrieved from https://cms.dot.gov/sites/dot.gov/files/docs/FY2016-BudgetEstimateFAA.pdf

FAA. (2017). FAA performance and accountability report. Retrieved from https://www.faa.gov/about/plans_reports/media/2017_FAA_PAR.pdf

Field, A. (2013). Discovering statistics using IBM SPSS statistics. Thousand Oaks, CA: Sage.

Hong-bing, D., \& Qing-qing, Z. (2015, June). Simulation of the effect of safety investment on flight safety level in the airlines. 2015 International Conference on Transportation Information and Safety (ICTIS) (pp. 780786). IEEE.

Kuffner, M. P., \& Perkins, R. (2009). Human factors assessment of runway status lights and final approach runway occupancy signal: FAA operational evaluations at Dallas Ft. Worth and San Diego International airports. In Eighth USA/Europe Air Traffic Management Research and Development Seminar (ATM2009).

Morrison, S. A., \& Winston, C. (2008). The effect of FAA expenditures on air travel delays. Journal of Urban Economics, 63(2), 669-678.

NTSB. (n.d.). Most wanted. Retrieved from https://www.ntsb.gov/ news/events/Pages/196.aspx

OIGDOT. (2008). FAA's implementation of runway status lights. Federal Aviation Administration Report Number AV-2008-021. Retrieved fromhttps://www.oig.dot.gov/sites/default/files/WEB_Final_RWSL.pdf

OIGDOT. (2018). FAA faces challenges in implementing and measuring the effectiveness of its 2015 runway safety Call to Action initiatives. Retrieved from https://www.oig.dot.gov/sites/default/files/ FAA\%20Runway\%20Safety\%20Initiatives\%5E6-27-18.pdf 
Rogerson, E. C., Lambert, J. H., \& Johns, A. F. (2013). Runway safety program evaluation with uncertainties of benefits and costs. Journal of Risk Research, 16(5), 523-539.

Schönefeld, J., \& Möller, D. P. F. (2012). Runway incursion prevention systems: A review of runway incursion avoidance and alerting system approaches. Progress in Aerospace Sciences, 51, 31-49.

Stewart, M. G., \& Mueller, J. (2013). Terrorism risks and cost-benefit analysis of aviation security. Risk Analysis, 33(5), 893-908.

Van Eekeren, R., Wright, S., \& Čokorilo, O. (2018). Early cost safety analysis of runway events. International Journal for Traffic \& Transport Engineering, 8(3), 261-270.

Weikel, D. (2012, April 12). More runway warning lights will be added at LAX to increase safety. Los Angeles Times. Retrieved fromhttps://latimesblogs.latimes.com/lanow/2012/04/lax-runways-gets-anew-round-of- warning-lights-to-increase-safety.html 


\section{Appendix A}

\section{Tables}

Table 1

Average Incursion Rates for Select Airports (1999-2007)

\begin{tabular}{|c|c|}
\hline Airport & Average Incursion Rate \\
\hline Los Angeles International (LAX) & 1.189 \\
\hline Dallas-Ft. Worth International (DFW) & 0.741 \\
\hline Ft. Lauderdale Executive (FXE) & 2.475 \\
\hline North Las Vegas (VGT) & 3.530 \\
\hline Palm Springs (PSP) & 2.336 \\
\hline
\end{tabular}

Table 2

Chi Square Goodness-of-fit: C Counts for LAX and DFW Airports

\begin{tabular}{|c|c|c|c|c|c|c|}
\hline Years & N & DF & Chi-Sq $^{\text {a }}$ & $\boldsymbol{\phi}$ & P-Value & $\begin{array}{c}\text { Direction } \\
\text { of } \boldsymbol{\Delta}\end{array}$ \\
\hline $\begin{array}{c}\text { LAX 2001-2012 v. } \\
\mathbf{2 0 1 3 - 2 0 1 7}\end{array}$ & 148 & 1 & 72.66 & 0.4909 & $<0.001$ & $\checkmark$ \\
\hline $\begin{array}{c}\text { DFW 2001-2004 v. } \\
\mathbf{2 0 0 5 - 2 0 1 7}\end{array}$ & 103 & 1 & 24.01 & 0.2331 & $<0.001$ & $\checkmark$ \\
\hline
\end{tabular}

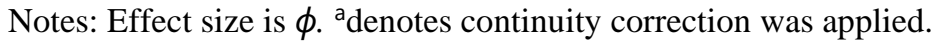

Table 3

Chi Square Goodness-of-fit: D Counts for LAX and DFW Airports

\begin{tabular}{|c|c|c|c|c|c|c|}
\hline Years & N & DF & Chi-Sq $^{\mathbf{a}}$ & $\boldsymbol{\phi}$ & $\boldsymbol{P}$-Value & $\begin{array}{c}\text { Direction } \\
\text { of } \boldsymbol{\Delta}\end{array}$ \\
\hline $\begin{array}{c}\text { LAX 2001-2012 v. } \\
\mathbf{2 0 1 3 - 2 0 1 7}\end{array}$ & 94 & 1 & 1.82 & 0.0193 & 0.177 & NA \\
\hline $\begin{array}{c}\text { DFW 2001-2004 v. } \\
\mathbf{2 0 0 5 - 2 0 1 7}\end{array}$ & 51 & 1 & 0.97 & 0.0190 & 0.324 & NA \\
\hline
\end{tabular}

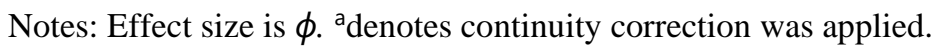


Table 4

Mann-Whitney $\mathrm{U}$ Tests for $A, B, C$, and D rates $-L A X$ and DFW Airports

\begin{tabular}{|c|c|c|c|c|}
\hline Years & $\begin{array}{l}\text { A rate } U, r, \\
\& p \text {-value }\end{array}$ & $\begin{array}{l}\text { B rate } U, r, \\
\& p \text {-value }\end{array}$ & $\begin{array}{l}\text { C rate } U, r, \\
\& p \text {-value }\end{array}$ & $\begin{array}{c}\text { D rate } \\
U, r, \& \\
p \text {-value }\end{array}$ \\
\hline LAX 2001-2012 v. 2013-2017 & $\begin{array}{c}27.5,0.156 \\
0.519\end{array}$ & $\begin{array}{c}28.0,0.07 \\
0.879\end{array}$ & $\begin{array}{c}3.0,0.69 \\
0.004^{*}\end{array}$ & $\begin{array}{l}22.0 \\
0.204 \\
0.399\end{array}$ \\
\hline DFW 2001-2004 v. 2005-2017 & $\begin{array}{c}22.0,0.196 \\
0.419\end{array}$ & $26.0,0,1.0$ & $\begin{array}{c}8.0,0.495 \\
0.041^{*}\end{array}$ & $\begin{array}{l}15.0 \\
0.302 \\
0.245\end{array}$ \\
\hline
\end{tabular}

Notes: $r$ is effect size. *denotes $p<0.05$. 


\section{Appendix B}

\section{Figures}

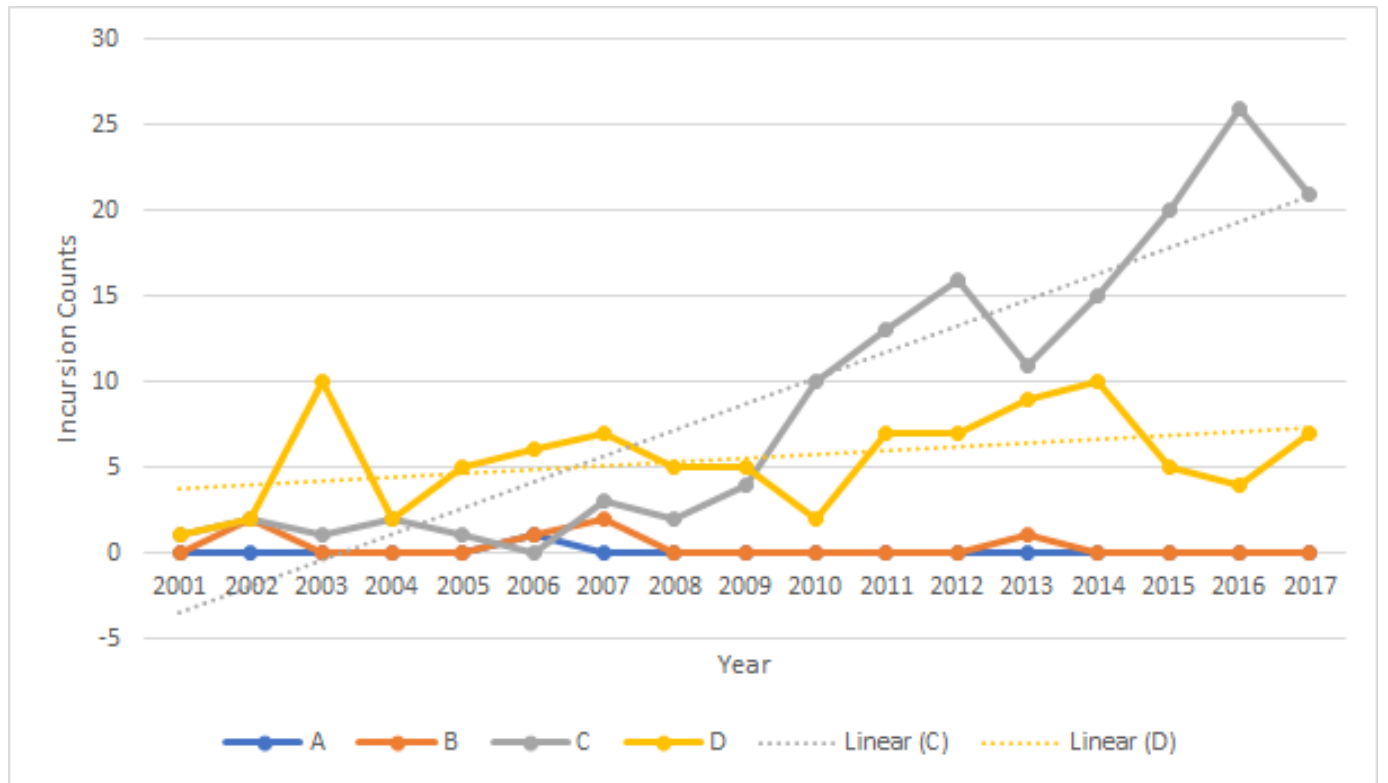

Figure 1. LAX Airport A, B, C, \& D severity counts of incursions 2001-2017 with linear trendlines. Note: trendlines for A \& B were negligible. 
International Journal of Aviation, Aeronautics, and Aerospace, Vol. 7 [2020], Iss. 1, Art. 2

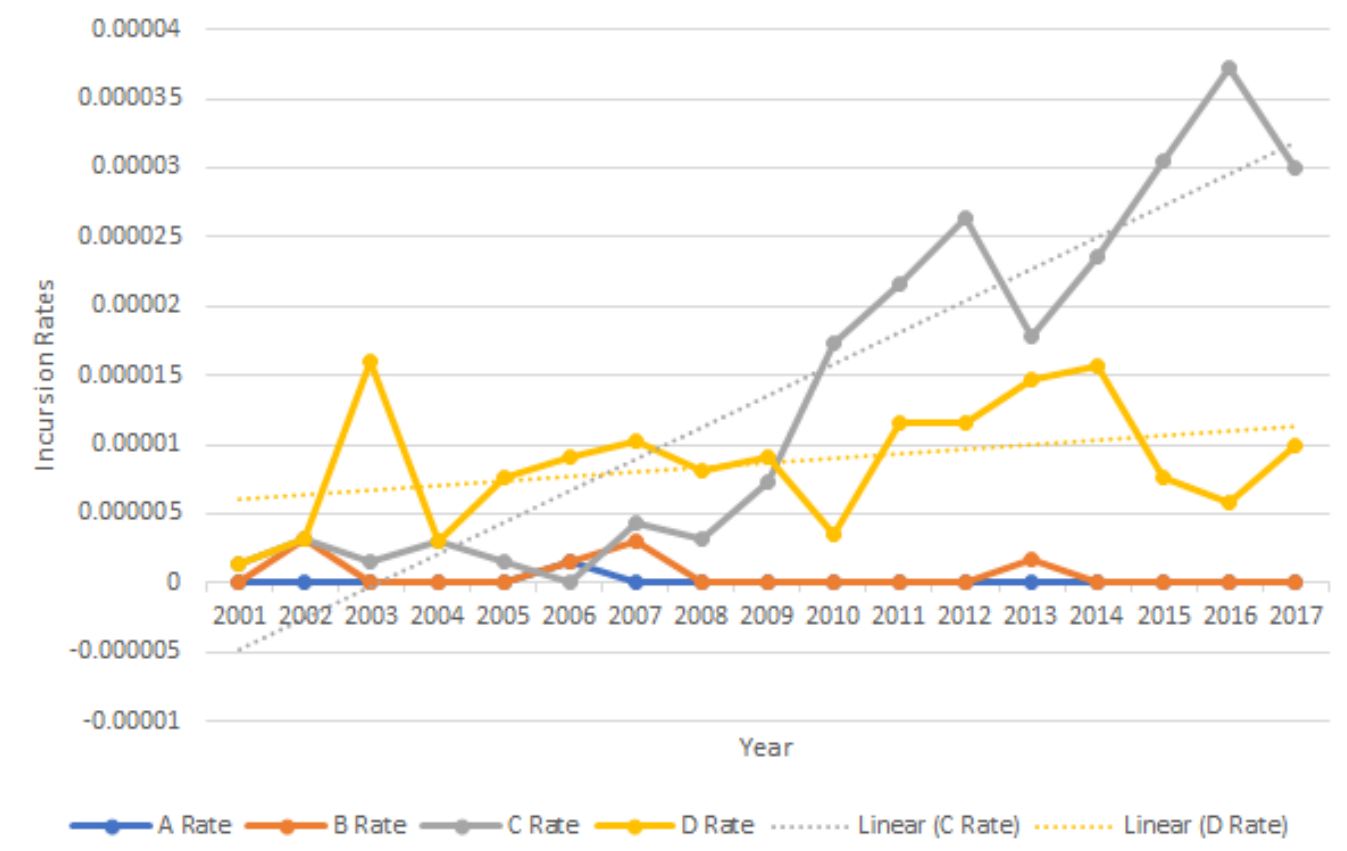

Figure 2. LAX Airport A, B, C, \& D severity rates of incursions 2001-2017 with linear trendlines. Notes: trendlines for $\mathrm{A} \& \mathrm{~B}$ were negligible. $R^{2} \mathrm{C}$ rate $=0.8439$; $\mathrm{D}$ rate $=$ 0.1388 . 


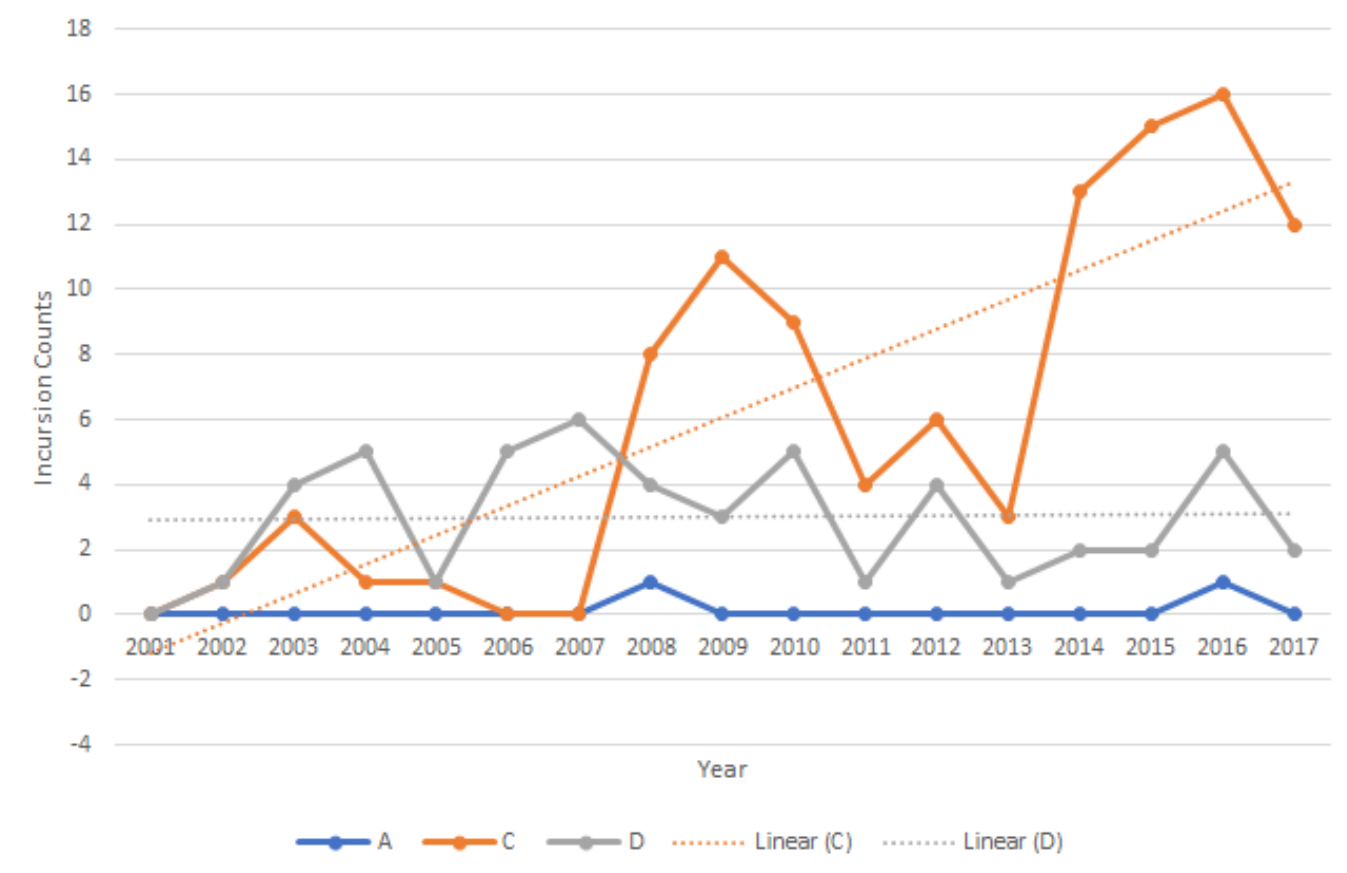

Figure 3. DFW Airport A, B, C, \& D severity rates of incursions 2001-2017 with linear trendlines. Notes: trendline for A was negligible; there were no B events. 


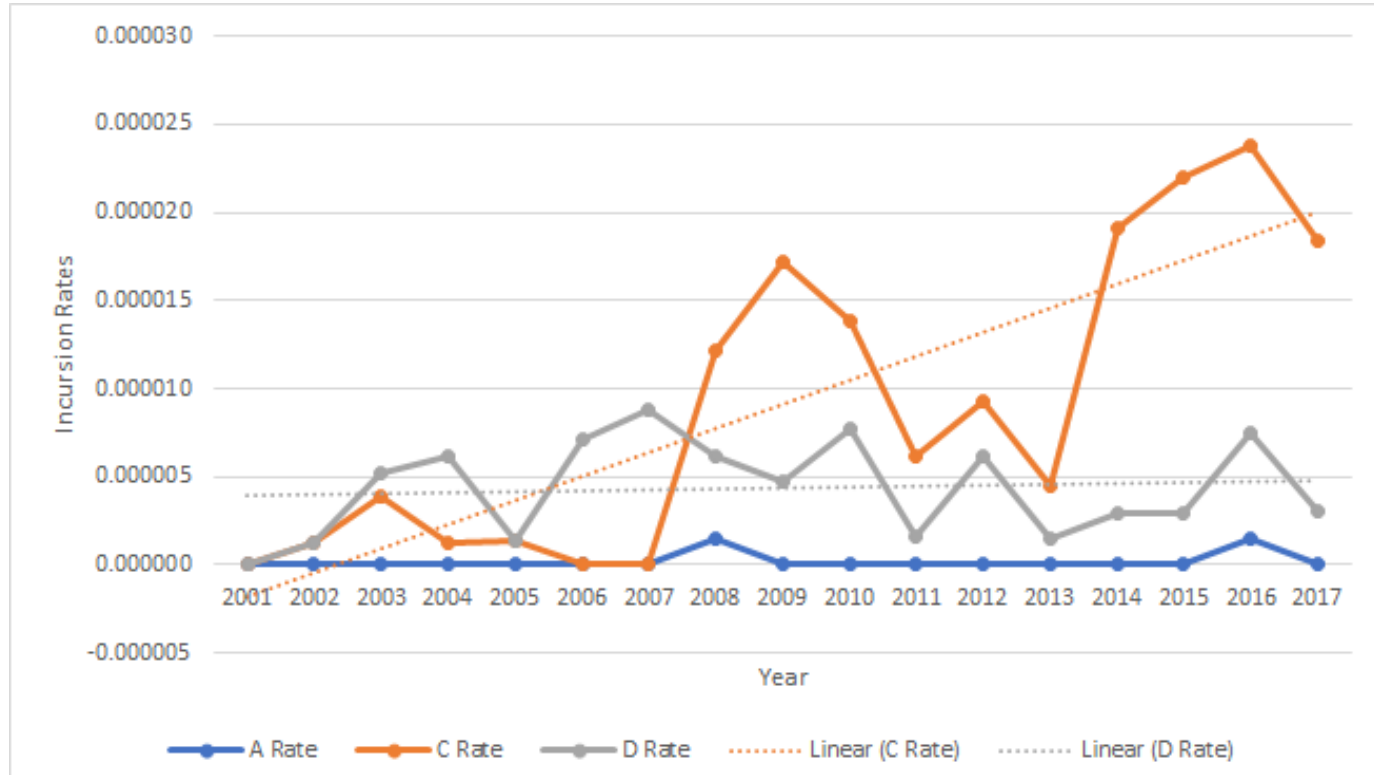

Figure 4. DFW Airport A, B, C, \& D severity rates of incursions 2001-2017 with linear trendlines. Notes: trendline for $\mathrm{A}$ was negligible; there were no $\mathrm{B}$ events. $R^{2} \mathrm{C}$ rate $=$ $0.6571 ;$ D rate $=0.0109$. 